\title{
Insights of professional activity at the stage of professionalization
}

\author{
Svetlana Zholudeva, Irina Ulybysheva* \\ South Federal University, 344000, Rostov-on-Don, Russia
}

\begin{abstract}
Specific character of a dynamic development of economy and society place demands on new highly-qualified personnel of any sphere professional activity, especially the sphere connected with interaction with people who have modern high-tech skills. Demands' changes on the subject of professional activity brings on a qualitative restructuring of professionalization's process, that facilitates an integration of educational and professional spheres with a conceptional, technological and theoretical supporting. Successful professional activity depends a lot upon a successful period of early professionalization that is impossible without proper provided insights of a profession. This article shows the results of an empirical study regarding the analysis of peculiarities of professional ideas of pre-service teachers. A specific attention is given to the problem of study of professional activity ideas effect at the stage of early professionalization, which changes during the period of ideas' transformation concerning professional activity and career building that is caused by the changes in the essence of professionalization from a socio normed event into an individual work of professional aimed at selfdetermination and self-actualization in profession.
\end{abstract}

Professionalization of a personality is studied in psychology as a rule in relation to an ontogenetic development of a person, taking into account personality, capacity, interests, establishment of professional consciousness on the basis of professional activity's ideas.

A lot of works is devoted to the study of professionalization process by scientists from different schools and approaches of psychological knowledge. Professionalization is the main process of person's development at his career (profession), which is focused on a qualitative transformation of a professional activity's subject.

Development of professionally successful person happens due to the working out natural contradictions appearing between the obtained level of person's development and society's demands, learning activity to the fully formed system of already formed knowledge, skills and also to the individually-psychological qualities of personality [1]. Consequently, the professionalization process means an individual professional becoming for every personality with a proper educational and personal path.

\footnotetext{
* Corresponding author: Iulybysheva@sfedu.ru
} 
Insights of professional activity accumulate such traits as: professional, personal and cultural development, skills of self-presentation, occupational contacts, building of development path in profession [2].

Analysis of theoretical approaches lets us make a conclusion that professional ideas are closely related to the real world. S.T. Dzheneryan in his studies notices that professional ideas get necessary development through the immediate support of professional environment where happens person's development as a professional [3].

Professional insights of pedagogues at studies by many researchers ( S.S. Martynova, E.M. Nikireev, E.I. Rogov, V.A. Slastenin, Barnhardt B., Ginns P., Magnus J.R., Peresetsky A.A.) are determined with the point of motivation sphere of person's professional activity which is defined by needs and expressed in interests, relations, welldirected efforts of professional's personality [4].

Insights about professional activity during the process of early professionalization can be regarded as a human factor of successful professional's creation. Professional activity's ideas carry an information about personality, talents and skills, abilities, focuses as well as the results of professional activity [5]. In this connection there is the understanding of personality as an active doer who is completely involved in the method of his own pragmatist existence.

Thus, ideas about professional activity include the trajectory of professional and personal development.

With the aim to define semantic features of the insights about professional activity have been used the techniques "Career anchors" E. Sheyna and "The study of motivational personality profile" Sh. Richa and P. Martina. Students of pedagogical departments have taken part in this research in Rostov on Don.

The analysis of obtained data has shown that professional ideas of pre-service teachers are formed on the basis of conation to reliable and steady (14\% those surveyed) working place for a long period of time.

The second significant semantic characteristic of insights about professional activity among the pre-service teachers is the career commitment to service $(13 \%)$. In this way during the professional activity pre - service teachers aspire to accomplish the need to realize the personal goals and moral and ethic aspirations. In this case the insights about professional activity will be founded upon the commitment among pre- service teachers to service and altruism.

The following significant semantic characteristic of insights about professional activity among the pre - service teachers is an orientation at career on the desire to integrate the lifestyles $(12,7 \%)$. The students' insights concerning professional activity from this group are based on integration of modern person's life aiming at harmony in life, the damage of professional self-realization.

The least showed characteristics concerning the content of ideas of professional activity is the orientation on professional competence $(11 \%)$, autonomy $(10 \%)$, challenge $(10 \%)$ and constant place of residence $(9 \%)$. The analysis of empirical data lets us make a conclusion that the pre-service teachers who took part in this research find the social recognition as the most significant in the process of professional activity and what is more they strive to take a certain socially approved status.

Students with such insights consider that it is possible to manage other people in order to obtain a general purpose, but management is not the goal of the entire profession. Important place here belongs to the autonomy and the freedom of professional actions.

The absence of pre - service teachers with a low career orientation level among of those surveyed is the essential for the interpretation of obtained empirical data. Therefore, the analysis of the results leads to insight that pre - service teachers meaningfully imbue the 
insights about professional activity with such positions as stability, confidence in the future, social safety, the ability to realize their altruistic needs and harmonize areas of life.

The study of motivational personality profile has demonstrated that motivating factors of professional activity that are the leading power of person's development at profession proved that the pre-service teachers that took part in this research have strong motivating factors. To these factors can be given the need for self-actualization $(21 \%)$, need for interesting and socially useful activity $(21 \%)$.

Pre-service teachers with such motivating factors domination are aimed at personal and professional growth are characterized with a strong need for constant advanced training, improvement of occupational skills. With the purpose to meet such needs it is necessary to create conditions for improvement professional knowledge level and skills though the courses, seminars, conferences and trainings. The analysis of obtained empirical data though the used method demonstrates the intention to an interesting and socially acceptable professional activity among the pre - service teachers.

To motivating factors that are not widely spread can be included the following: the need for high wages $(5 \%)$; the need for good working conditions $(5 \%)$; need for recognition $(4 \%)$; the need for a clear structuring of the work (4\%); the need to set complex goals for yourself and achieve them (3\%); desire to avoid routine (3\%); the need for change $(3 \%)$ and the need to be creative $(2 \%)$.

The discovered relationship between the following scales: motivation of selfactualization and integration of lifestyles, independence, profession stability; motivation of socially useful activity and commitment to service, makes possible the deduction that there is an interrelation between the motivating profession profile and the insights about the future profession that the pre-service teachers have.

Analysis and interpretation of the obtained data let us come to a conclusion that during the professionalization process of pre-service teachers prevail professional activity's ideas connected with a desire for self-actualization through personal development, professional autocompetition and building a successful career ladder.

Personal growth of the pre-service teachers' professional activity is expressed in an autonomy conation and freedom of professional actions. The essential component of professional activity's ideas among the respondents at the stage of professionalization is their desire to socially useful and essential activity. Along with changes in ideas about professional activity there are changes relating professional expectations of pre-service teachers.

Pre-service teachers' professionalization goes along with a constant comparison of individual person's capabilities with profession's demands [6]. Personal qualities of subject (an individual) in professionalization process are compared with such components of professional activity as tasks, working conditions, disputes that leads to an inconsistency between the demands of professional activity and person's development level. Such inconsistency has the role of the driving force of professional's development.

Consequently, early recognition of motivating personality profile of a professional and career orientation makes possible to form professional ideas in a job of an organizing psychologist in cooperation with an institute of higher education - employer, that will let to provide a more successful professionalization, short-term adaptation and a high level of employee's work satisfaction.

\section{References}

1. K.C. Richards, CE. Campenni, J.L Muse-Burke, J. of ment. heal. couns. 32 (3), (2010)

2. B. Barnhardt, P. Ginns, Eth. and Beh. 27 (4), (2017)

3. S.T. Dzhaneryan, D.I. Gvozdeva, E.A. Panina, J. of p. and app. Math. 119 (17), (2018) 
4. J.R. Magnus, A.A. Peresetsky, Frontiers in Psychology. 8, (2018)

5. E.I. Rogov World of Science. 6(4), (2018)

6. M.L. Khatulova, I.V. Abakumova, Cont. of Rus. W. pract. Conf. with an int. part (2018) 